\title{
BMJ Open A protocol for prospective studies of 25-hydroxyvitamin D, leptin and body mass index in relation to cutaneous melanoma incidence and survival
}

\author{
Jo Steinson Stenehjem, ${ }^{1}$ Tom K Grimsrud, ${ }^{1}$ Judith R Rees, ${ }^{2,3}$ Linda Vos, ${ }^{1}$ \\ Ronnie Babigumira, ${ }^{1}$ Marit B Veierød, ${ }^{4}$ Trude Eid Robsahm ${ }^{1}$
}

To cite: Stenehjem JS, Grimsrud TK, Rees JR, et al. A protocol for prospective studies of 25-hydroxyvitamin $D$, leptin and body mass index in relation to cutaneous melanoma incidence and survival. BMJ Open 2017;7:e014829. doi:10.1136/ bmjopen-2016-014829

Received 21 October 2016 Revised 22 March 2017 Accepted 31 March 2017

\section{CrossMark}

${ }^{1}$ Department of Research, Cancer Registry of Norway, Oslo, Norway

${ }^{2}$ New Hampshire State Cancer Registry, Lebanon, New Hampshire, USA

${ }^{3}$ Department of Epidemiology, Geisel School of Medicine at Dartmouth, Lebanon, New Hampshire, USA

${ }^{4}$ Oslo Center for Biostatistics and Epidemiology, Department of Biostatistics, University of Oslo, Oslo, Norway

Correspondence to Dr Jo Steinson Stenehjem; jo. stenehjem@kreftregisteret.no

\section{ABSTRACT}

Introduction The incidence and mortality rates of cutaneous melanoma (CM) are increasing among fairskinned populations worldwide. Ultraviolet radiation (UVR) is the principal risk factor for $\mathrm{CM}$, but is also the main source of 25-hydroxyvitamin D (25(OH)D), which has been associated with reduced risk and better prognosis of some cancer types. However, both low and high 25(OH)D levels have been associated with increased risk of $\mathrm{CM}$. Obesity as measured by body mass index (BMI) is associated with risk of several cancers and has also been suggested as a risk factor for $\mathrm{CM}$, and may also be related to insufficient 25(OH)D and/or high leptin levels. Moreover, contracting a CM diagnosis has been associated with increased risk of developing second cancer. We aim to study whether low prediagnostic serum levels of $25(\mathrm{OH}) \mathrm{D}$, high prediagnostic levels of BMI and high serum leptin levels influence CM incidence, Breslow thickness and CM mortality, and risk of second cancer and survival after a CM diagnosis.

Methods and analysis Cohort and nested case-control studies will be carried out using the population-based Janus Serum Bank Cohort (archival prediagnostic sera, BMI, smoking and physical activity), with follow-up from 1972 to 2014. Additional data will be received from the Cancer Registry of Norway, the national Cause of Death Registry, Statistics Norway (education and occupation) and exposure matrices of UVR. Time-to-event regression models will be used to analyse the cohort data, while the nested case-control studies will be analysed by conditional logistic regression. A multilevel approach will be applied when incorporating group-level data.

Ethics and dissemination The project is approved by the Regional Committee for Medical Research Ethics and is funded by the Norwegian Cancer Society. Results will be published in peer-reviewed journals, at scientific conferences and in the news media.

\section{INTRODUCTION}

\section{Rationale and evidence gaps}

Ultraviolet radiation (UVR) is a recognised human carcinogen and the principal environmental risk factor for cutaneous melanoma $(\mathrm{CM}),{ }^{1}{ }^{2}$ while skin characteristics such as skin sensitivity and number of naevi indicate CM susceptibility. ${ }^{3-7} \mathrm{CM}$ incidence and

\section{Strengths and limitations of this study}

- Linkage of independent, national data sources by use of a unique personal identification number for a comprehensive research file and complete control of loss to follow-up.

- Prediagnostic serum samples assuring a true prospective relationship between exposures and cancer, limiting bias introduced by reverse causality.

- Lifetime ambient ultraviolet radiation (UVR) exposure data (UVA, UVB and erythemally weighted UV) and group-level data on sunburns, sunbathing vacations and solarium use capturing variations in age, time period and county of residence.

- Ambient UVR exposure and data on sunburns, sunbathing vacations and solarium use can only be linked to the Janus Cohort on a group level.

- Lack of data on pigmentary characteristics and naevi.

mortality rates have been increasing in fairskinned populations worldwide the past decades, and CM is currently the third most common cancer in Europe after cancers of the colon/rectum and the lung. ${ }^{89}$ In Norway, CM incidence has increased more than 3\% annually between 1982 and 2011 and has been projected to continue to rise. ${ }^{9}$ Excess UVR exposure is likely the major cause of this increase ${ }^{10}$ but also low vitamin $\mathrm{D}$ levels and obesity have been suggested to play a role. ${ }^{1112}$

Vitamin D synthesis in the skin is initiated by UVR exposure to the skin surface at wavelengths of $290-320 \mathrm{~nm}$, which converts 7-dehydrocholesterol in the keratinocytes to previtamin D3 (cholecalciferol). Together with previtamin D2 (ergocalciferol), previtamin D3 may also be obtained by diet. Both previtamin D2 and D3 are then hydroxylated in the liver to 25-hydroxyvitamin D $(25(\mathrm{OH}) \mathrm{D})$, which represents the circulating storage form of vitamin D. A second hydroxylation in the kidney converts vitamin 
$\mathrm{D}$ to its biologically active form 1, 25-hydroxyvitamin D $(1,25(\mathrm{OH}) \mathrm{D}),{ }^{13} 14$ which has been associated with anticancer mechanisms. ${ }^{1315-17}$ Based on four studies, a recent meta-analysis reported a summary relative risk of $\mathrm{CM}$ of 1.46 (95\% CI: 0.60 to 3.53) for the highest compared with the lowest (reference) quantile of $25(\mathrm{OH}) \mathrm{D} .{ }^{12}$ In three of these studies, risks increased with increasing $25(\mathrm{OH}) \mathrm{D}$ serum levels, while the fourth study reported the opposite. ${ }^{18-21}$ None of these studies individually showed any statistically significant associations, and the inconclusive results may be due to difference in statistical power, the covariate adjustments, whether CM cases had a cancer history or not, and whether serum was sampled before or after the CM diagnosis. Several recent studies have reported an inverse association between Breslow thickness and 25(OH)D serum level at diagnosis. ${ }^{20}$ 22-25 As both tumour thickness and $25(\mathrm{OH}) \mathrm{D}$ level were measured at the same time in these studies, these associations may have been affected by reverse causality. ${ }^{26} 27$ However, for prognosis after a CM diagnosis, higher diagnostic $25(\mathrm{OH}) \mathrm{D}$ levels have been shown to predict lower risk of relapse and increased survival, independent of Breslow thickness. ${ }^{22}{ }^{24} \mathrm{~A}$ recent study ascribed the effect on $\mathrm{CM}$ survival to change in $25(\mathrm{OH}) \mathrm{D}$ during follow-up from $\mathrm{CM}$ diagnosis to death, and not the $25(\mathrm{OH}) \mathrm{D}$ level at diagnosis. ${ }^{28}$

Low 25(OH)D levels are more frequent in obese persons, suggesting that $25(\mathrm{OH}) \mathrm{D}$ deficiency is associated with obesity and vice versa. ${ }^{29-33}$ Obesity as measured by body mass index (BMI) above $30 \mathrm{~kg} / \mathrm{m}^{2}$ has been positively associated with CM risk in males, but results for women are ambiguous and possibly confounded by personal habits as obese women may refrain from sunseeking behaviour compared with their normal-weight peers. ${ }^{11}$ Further, diet-induced obesity has been found to increase CM progression in mice models. ${ }^{34}$ The biological mechanism underlying an obesity-induced increase in CM incidence is not well understood, although a hyperglycaemia hypothesis has been suggested. ${ }^{35}$ Another hypothesis suggests that adipocytes produce high levels of vascular endothelial growth factor, associated with visceral fat, which contributes to angiogenesis and tumour growth. ${ }^{36}$

The metabolic hormone leptin may be a risk factor for both $\mathrm{CM}$ and $\mathrm{CM}$ progression. Leptin is released by adipose tissue and plays an important role in the regulation of insulin sensitivity and weight regulation. ${ }^{37}{ }^{38}$ Increased diagnostic serum levels of leptin have been associated with increased CM risk, possibly caused by a leptin-induced increase in neoangiogenesis, reduction of melanogenesis and a decreased capacity of the melanocytes' DNA repair. ${ }^{39}{ }^{40}$ Recent studies have demonstrated that leptin receptors are present in melanoma cell lines that proliferate in response to leptin, and that leptin bound to its receptor stimulates melanoma growth. ${ }^{41-44}$

After a CM diagnosis, there is an increased risk of diagnosis of additional CM, as well as other cancers. ${ }^{45}{ }^{46}$ For example, the risk of lymphoma before or after CM has received increased focus. ${ }^{47}$ Immune perturbation has been suggested to contribute to the development of CM after non-Hodgkin's lymphoma (NHL) subtypes such as chronic lymphocytic leukaemia/small lymphocytic lymphoma. ${ }^{48}$ As for $\mathrm{CM}$, low $25(\mathrm{OH}) \mathrm{D}$ serum levels have also been associated with reduced survival and poor prognosis after NHL, ${ }^{49} 50$ which raises the question of whether low $25(\mathrm{OH}) \mathrm{D}$ could alter the risk of lymphoma as a second cancer after CM or vice versa.

\section{Aims and hypotheses}

The interplay between $25(\mathrm{OH}) \mathrm{D}$ and obesity and their relation to $\mathrm{CM}$ is poorly described, and increased knowledge of these factors is warranted to improve CM prevention and prognosis. In the present study protocol, we propose a set of prospective cohort and nested casecontrol studies with the primary aim of examining BMI and serum levels of $25(\mathrm{OH}) \mathrm{D}$ and leptin in relation to $\mathrm{CM}$ risk, Breslow thickness and mortality, and risk of second cancer and survival after a CM diagnosis. As a secondary aim, we propose a nested case-control study of lymphoma risk after $\mathrm{CM}$ and vice versa, in relation to serum levels of $25(\mathrm{OH}) \mathrm{D}$ and leptin.

We hypothesise that:

1. High prediagostic BMI $\left(\geq 30 \mathrm{~kg} / \mathrm{m}^{2}\right.$, quantiles, continuous) is associated with

- Increased CM risk, Breslow thickness and mortality;

- Reduced survival after a CM diagnosis;

- Increased risk of contracting CM followed by a second cancer $(\mathrm{n}=292851)$;

- Increased risk of second cancer among $\mathrm{CM}$ survivors $(\mathrm{n} \approx 3000)$.

2. High prediagnostic serum levels of leptin $(>4 \mathrm{ng} / \mathrm{mL}$, highest quantile, continuous) and low prediagnostic $25(\mathrm{OH}) \mathrm{D}$ levels $\quad(<30 \mathrm{nmol} / \mathrm{L}$, lowest quantile, continuous) are associated with

- Increased CM risk and Breslow thickness;

- Reduced survival after a CM diagnosis;

- Increased risk of contracting CM followed by a second cancer compared with no cancer history;

- Increased risk of second cancer among CM survivors;

- Increased lymphoma risk after a CM diagnosis and vice versa compared with no cancer history.

\section{METHODS AND ANALYSIS}

Study population and data sources

Janus Serum Bank Cohort

This project is based on the Janus Serum Bank Cohort, a population-based biobank for prospective cancer studies containing serum samples and questionnaire data from 292851 Norwegians who participated in five health surveys 1972-2003. A detailed description of the Janus Serum Bank Cohort (hereafter Janus Cohort), its data and establishment, is published elsewhere. ${ }^{51}$ The Janus Cohort includes participants from the following surveys: 




Figure 1 Overview of linkage between different data sources. BMI, body mass index; ERY, erythemally weighted UVR; PIN, personal identification number; UVR, ultraviolet radiation.

1. The Oslo Study I (1972-1973) invited men residing in Oslo aged 20-49 years.

2. The Norwegian Counties Study was carried out as a three-wave survey (1974-1978, 1977-1983 and 19851988), inviting men and women aged 20-49 years residing in Finnmark, Oppland or Sogn og Fjordane.

3. Oslo Age 40 Programme invited men and women aged 40 residing in Oslo 1981-1999.

4. The National Age 40 Programme triennially invited all men and women aged 40-42 years in all Norwegian counties during 1985-1999.

5. The TROFINN Health Study invited all men and women aged 30-75 years residing in Troms and Finnmark in 2001-2003.

\section{Blood serum samples}

The Janus Cohort has detailed sample information including date of sample collection and county of residence at sample collection. The samples have been stored at $-25^{\circ} \mathrm{C}$ for up to 43 years. ${ }^{51}$ Serum samples of $25(\mathrm{OH}) \mathrm{D}$ and leptin have been demonstrated to have high stability after long-term storage, ${ }^{52}$ and previous studies have shown that serum from the Janus Cohort is well suited for analyses of $25(\mathrm{OH}) \mathrm{D}^{54} 55$ and leptin. ${ }^{56} 57$ Although the storage condition at $-25^{\circ} \mathrm{C}$ is not ideal, a possible time-dependent degradation may be partly compensated for by matching cases and controls on time of blood draw.

Height and weight measurements and questionnaire data

Together with blood sample collection, standardised height and weight measurements were taken by trained personnel. Participants in the surveys were also asked to complete questionnaires on smoking habits, alcohol consumption, diet, physical activity, use of medications etc. Slightly different questionnaires (different wording and number of response categories) were used in the five health surveys, and a set of variables has been harmonised. ${ }^{58}$ For the present project, the following variables are available: height $(\mathrm{cm})$, weight $(\mathrm{kg}), \mathrm{BMI}\left(\mathrm{kg} / \mathrm{m}^{2}\right.$ and categorised as 12-18.49, 18.5-24.9, 25.0-29.9, $\geq 30),{ }^{59}$ smoking status (never, former, current), cigarettes per day (1-9, $10-14, \geq 15)$, years of smoking $(1-9,10-29, \geq 30)$, time since smoking cessation ( $<3$ months, 3 months-1 year, $1-5$ years, $>5$ years), level of total physical activity (inactive, low, medium, high) and level of physical activity at work (sedentary, walking, walking and lifting, heavy physical work).

Linking the Janus Cohort to population-based registries

Every resident in Norway is assigned a unique 11-digit personal identification number (PIN), which ensures a 
correct linkage of the Janus Cohort to population-based registries and databases as described below and in figure 1 .

\section{Population-based registries}

The Cancer Registry of Norway (CRN) has registered all new cancer diagnoses in Norway since 1953. Reporting of incident cancers to the CRN is compulsory by law, and information from pathologists, general practitioners, the Norwegian Patient Registry and the Norwegian Cause of Death Registry ensures a high degree of completeness (overall 98.8\%). ${ }^{3}$ For the present project, incident cancers from 1972 through 2014 will be linked to the Janus Cohort. The following cancer information will be used: date of diagnosis (month and year), tumour localisation (International Classification of Diseases seventh revision (ICD-7 codes) converted into ICD-10 codes), histology (codes from ICD-Oncology second and third revisions), clinical stage $($ local=no metastases, regional=metastasis in regional lymph nodes or surrounding area, distant=distant metastasis) and Breslow thickness ( $\mathrm{mm}$ ).

Date and cause of death (death from cancer and death from causes other than cancer) will be obtained from the Cause of Death Registry and vital status (alive, emigrated or dead) with corresponding dates will be obtained from the National Population Registry.

Data on occupation at baseline (categorised as indoor/ outdoor/mixed and high risk/medium risk/low risk for UVR exposure) and highest attained educational level at baseline (none, compulsory, upper secondary, college/ university) will be obtained from Statistics Norway.

\section{UVR exposure matrices}

County-specific, yearly average doses of ultraviolet A (UVA), ultraviolet B (UVB) and erythemally weighted UVR (ERY) will be calculated and assigned to each participant, according to place of residence, at baseline and cumulated throughout follow-up (ie, until cancer, emigration, death or 31 December 2014, whichever occurs first). The UVR exposure matrices will be based on measurement data from UV-network stations operated by the Norwegian Radiation Protection Authority and on modelled values as described by Medhaug et al. ${ }^{60}$ Furthermore, age-specific, county-specific and time period-specific data on sunburns, sunbathing vacations and solarium (women only) use will be linked to the Janus Cohort on a group level as derived from questionnaire data collected in the Norwegian Women and Cancer study. ${ }^{61}{ }^{62}$ Surveys conducted by the Norwegian Cancer Society show small gender differences with respect to frequency of sunburns and sunbathing vacations among Norwegian women and men. ${ }^{63}$ This is also supported by almost identical CM incidence rates between men and women in Norway in the past 60 years. ${ }^{64}$

\section{Study designs}

Study l: a prospective cohort study

In a prospective cohort study among all 292851 individuals in the Janus Cohort (study sample I in figure 2), we will explore baseline BMI in relation to $\mathrm{CM}$ risk, Breslow thickness and mortality (hypothesis 1.1), survival after a $\mathrm{CM}$ diagnosis (hypothesis 1.2) and risk of second cancer after CM (hypotheses 1.3 and 1.4). Hypotheses 1.3 and 1.4 differ by use of study sample; hypothesis 1.3 includes all 292851 individuals in the Janus Cohort, while hypothesis 1.4 includes only the $3000 \mathrm{CM}$ cases. Sex-specific analyses exploring the potential confounding effects from age, UVR exposure, smoking and education will be conducted for all analyses in study I.

\section{Studies II-IV: prospective nested case-control studies}

Three prospective case-control studies will be nested within the Janus Cohort (study samples II-IV in figure 2). For serum analyses, the nested case-control design is cost-efficient compared with the cohort design as only a limited number of CM cases and cancer-free controls are selected and matched using an incidence-density sampling scheme. ${ }^{65}$ Also, the nested case-control design takes advantage of the prospective nature of the cohort study by using data and serum samples collected before any cancer diagnosis, thereby reducing the potential for bias. Table 1 gives a complete description of the case, control and matching criteria.

\section{Study II}

Study II will examine CM risk and Breslow thickness according to prediagnostic serum levels of $25(\mathrm{OH})$ $\mathrm{D}$ and leptin (hypothesis 2.1). We will study CM cases (II a; figure 2) without a history of cancer and controls alive and without a cancer history at the time of the case diagnosis (II b). We will include one control per case, matched on sex, age at serum sampling and season due to seasonal variation in $25(\mathrm{OH}) \mathrm{D}$ levels (table 1$)$. UVR exposure, smoking and education will be adjusted for. Survival analysis (as in study I) will be undertaken on
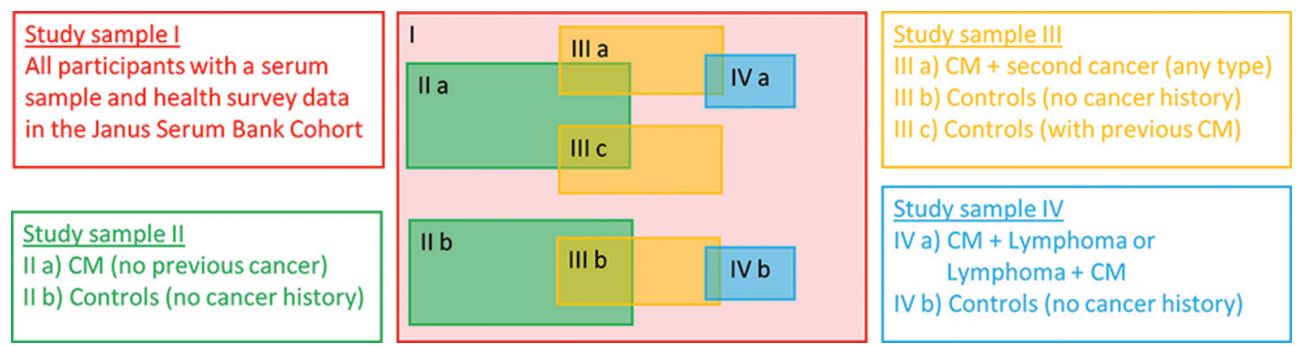

Figure 2 Overview of study samples and overlap between cases and controls between studies. 
Table 1 Overview of case, control and matching criteria for studies II-IV

\begin{tabular}{|c|c|c|c|}
\hline & Study II & Study III & Study IV \\
\hline \multicolumn{4}{|l|}{ Case criteria } \\
\hline Cases (n) & 700 & 345 & 60 \\
\hline Definition & $\begin{array}{l}\text { CM cases without a } \\
\text { cancer history (not tied } \\
\text { on date with another } \\
\text { diagnosis) }\end{array}$ & $\begin{array}{l}\text { Second cancers (any type) after first primary CM } \\
\text { diagnosis }\end{array}$ & $\begin{array}{l}\text { Lymphoma after first } \\
\text { primary CM diagnosis or } \\
\text { vice versa }\end{array}$ \\
\hline Age at diagnosis & \multicolumn{3}{|l|}{$<75$ years } \\
\hline Year of diagnosis & \multicolumn{3}{|l|}{$<2009$} \\
\hline $\begin{array}{l}\text { Minimum time } \\
\text { from blood draw to } \\
\text { diagnosis }\end{array}$ & \multicolumn{3}{|l|}{2 years } \\
\hline Sex & \multicolumn{3}{|l|}{ Male or female } \\
\hline \multicolumn{4}{|l|}{ Control criteria } \\
\hline Control group & II b & III b & IV b \\
\hline Controls (n) & 700 & 345 & 180 \\
\hline
\end{tabular}

Selection Random sampling with replacement from a pool of available controls

\section{Matching criteria}

$\begin{array}{ll}\begin{array}{l}\text { Sex } \\ \text { Age at blood draw }\end{array} & \begin{array}{l}\text { Same sex as case } \\ \pm 2 \text { years from age of case at blood draw. Stepwise extension by } \pm 3 \text { months up to } \pm 3 \text { years if } \\ \text { necessary }\end{array} \\ \begin{array}{ll}\text { Time period of blood } \\ \text { draw }\end{array} & \begin{array}{l}\text { The following 3-month intervals: (a) December-February, (b) March-May, (c) June-August, (d) } \\ \text { September-November }\end{array} \\ \text { Date of CM diagnosis } & \begin{array}{l}\text { Only applies to control group III c: } \pm 6 \text { months. Stepwise extension by } \pm 1 \text { months up to } \pm 1 \text { year if } \\ \text { necessary. }\end{array}\end{array}$

*9727, 9728, 9729, 9835, 9836, 9837, 9670, 9823, 9731, 9734, 9732, 9733, 9675, 9678, 9679, 9680, 9684, 9591, 9760, 9671, 9761, 9762, 9673, 9690, 9691, 9695, 9698, 9687, 9826, 9689, 9699, 9764, 9700, 9701, 9709, 9718, 9708, 9702, 9705, 9714, 9716, 9717, 9948, 9719, 9827, 9831, 9834 9833, 9940, 9820, 9832 9590, 9750.

†Allow only common cancers (colon, breast, prostate, skin and lung only) after date of diagnosis of case to conserve sera of rare cancers for later studies.

CM, cutaneous melanoma; ICD-10, International Classification of Diseases, 10th revision.

the subsample of CM cases (II a) with measured $25(\mathrm{OH})$ $\mathrm{D}$ and leptin (hypothesis 2.2). Covariates included in study I will be taken into account.

\section{Study III}

In study III, we will examine the risk of second cancer after a CM diagnosis according to prediagnostic serum levels of $25(\mathrm{OH}) \mathrm{D}$ and leptin (hypotheses 2.3 and 2.4). CM cases with a second cancer (III a; figure 2) and controls without a cancer history at the time of the second cancer diagnosis (III b) will be selected to address hypothesis 2.3. For hypothesis 2.4, controls with a CM diagnosis at the time of the second cancer diagnosis will be selected (III 
c). We will include one control per case, matched on sex, age at serum sampling and season of serum sampling (table 1). In addition, control group III c will be matched on date of the CM diagnosis (table 1). Covariates included in studies I-II will be taken into account.

\section{Study IV}

A group including cases (IV a; figure 2) with CM before lymphoma or vice versa and controls (IV b) with no cancer history at the time of the second cancer diagnosis will be examined according to prediagnostic serum levels of $25(\mathrm{OH}) \mathrm{D}$ and leptin (hypothesis 2.5). All case-control pairs will be matched on sex, age at serum sampling and season of serum sampling (table 1). Covariates included in studies I-III will be taken into account.

\section{Power and sample size calculations \\ Study 1}

With the large study sample ( $\mathrm{n}=292851)$, including more than 3000 CM cases by 31 December 2014, we have sufficient statistical power to reveal minor risk differences between the BMI categories, normal weight (18.5-24.9 kg/ $\left.\mathrm{m}^{2}\right)$, overweight $\left(25-29.9 \mathrm{~kg} / \mathrm{m}^{2}\right)$ and obese $\left(\geq 30 \mathrm{~kg} / \mathrm{m}^{2}\right)$. Thus, further power calculation is not conducted.

\section{Studies II-IV}

Study II will include $700 \mathrm{CM}$ cases of the approximately 3000 available. Study III will include 345 cases with a second primary cancer after CM and study IV will include 60 cases of lymphoma after $\mathrm{CM}$ or vice versa, which were the total number of cases in the Janus Cohort by 31 December 2014. Table 2 shows the smallest detectable OR according to assumed proportion of controls exposed to low serum levels of $25(\mathrm{OH}) \mathrm{D}$ and high leptin levels when using a power of 0.80 and a significance level of 0.05 . The assumed proportions of exposed controls were based on previous studies conducted on serum samples from the Janus Cohort. For $25(\mathrm{OH}) \mathrm{D}$, a study on prostate cancer reported that $4.4 \%$ and $30.6 \%$ of the controls had $25(\mathrm{OH}) \mathrm{D}$ levels below $30 \mathrm{nmol} / \mathrm{L}$ and $50 \mathrm{nmol} / \mathrm{L}$, respectively. ${ }^{54}$ For leptin, a study on colon cancer reported that

\begin{tabular}{|c|c|c|c|}
\hline $\begin{array}{l}\text { Proportion } \\
\text { of exposed } \\
\text { controls }\end{array}$ & $\begin{array}{l}\text { Study II } \\
\text { Cases=700, } \\
\text { ratio=1:1 }\end{array}$ & $\begin{array}{l}\text { Study III } \\
\text { Cases=345, } \\
\text { ratio=1:1 }\end{array}$ & $\begin{array}{l}\text { Study IV } \\
\text { Cases=60, } \\
\text { ratio=1:3 }\end{array}$ \\
\hline $5 \%$ * & 1.82 & 2.26 & 3.81 \\
\hline $30 \% \dagger$ & 1.37 & 1.57 & 2.34 \\
\hline 20\%‡ & 1.43 & 1.65 & - \\
\hline
\end{tabular}

${ }^{*}$ Exposure $=25(\mathrm{OH}) \mathrm{D}<30 \mathrm{nmol} / \mathrm{L}$. $\dagger$ Exposure $=25(\mathrm{OH}) \mathrm{D}<50 \mathrm{nmol} / \mathrm{L}$. †Exposure $=$ high serum leptin levels $\geq 4.1 \mathrm{ng} / \mathrm{mL}$ ). 25(OH)D, 25-hydroxyvitamin D.
$20 \%$ of the controls had a leptin level of $4.1 \mathrm{ng} / \mathrm{mL}$ or higher. ${ }^{56}$

\section{Data management \\ Case-control selection}

As indicated in figure 2, there will be some overlap between cases and controls between the studies. CM cases (II a) will be sampled at random from all available CM cases in the Janus Cohort, independent of second cancer status. However, some of the CM cases (II a) may have developed a new cancer and then be eligible for use in study III as CMs with a second cancer (III a). Controls (II b) will be sampled at random with replacement (incidence-density sampling) from the Janus Cohort and matched to CM cases (II a). Also, controls (II b) matched to the CM cases (II a) who developed a second cancer (III a) will be eligible for use in study III (group III b) if they are alive, resident and cancer-free at the time of the $\mathrm{CM}$ cases' second cancer (III a). Cases from study II (II a) may be reused as controls in study III (III c) if they fulfil the matching criteria (table 1). The remaining case-control pairs for study III will be sampled from the Janus Cohort. Study IV will follow the same approach as studies II and III with respect to reuse. A picking list of unique serum samples for all studies will be prepared by a data manager for the Janus Serum Bank Cohort laboratory team.

\section{Laboratory analyses}

The Janus Serum Bank laboratory team will send $220 \mu \mathrm{L}$ aliquots of serum to the Hormone Laboratory at Oslo University Hospital for analyses of $25(\mathrm{OH}) \mathrm{D}$ and leptin. The laboratory participated in the Vitamin D External Quality Assessment Scheme for total 25(OH)D. The Hormone Laboratory is accredited by the Norwegian Accreditation as a testing laboratory and complies with the requirements of the NS-EN ISO/IEC 17025 standards.

Serum concentrations of $25(\mathrm{OH}) \mathrm{D}$ will be determined by an in-house developed liquid chromatography/tandem mass spectrometry method. In brief, after protein precipitation, 25(OH)D will be extracted from samples using phospholipid depletion plates. Separation is achieved by reversed-phase chromatography and the isobaric C3 epimer 3-epi-25 $(\mathrm{OH}) \mathrm{D} 3$ will be separated from 25(OH) D3. Mass spectrometric detection will be performed by electrospray ionisation and triple quadruple ion separation (multiple reaction monitoring). ${ }^{66}$ Serum concentrations of leptin will be determined by using EMD Millipore Human Leptin Radioimmunoassay as described in Lee $e t a l^{67}$

Hormone Laboratory staff will be blinded to casecontrol status. Two identical quality control (QC) samples with serum from a pool of several persons will be placed on each batch. These two QC samples will change position for each new batch to avoid bias from weak spots in the machine/kit and will thus take into account both inter-batch variability and intra-batch variability. Each case-control pair will be placed and analysed on the same batch. 


\section{Statistical methods}

In the cohort studies, we will use Poisson and Cox regression and estimate relative risks with 95\% CIs. Spline models will also be explored if a non-linear relationship between exposure and outcome is assumed. In the nested case-control studies, conditional logistic regression will be applied to estimate ORs with 95\% CIs. A multilevel approach will be applied for analyses containing group-level data. Directed acyclic graphs will be used in the process to select variables to include in the statistical models. Confounding variables will be included in the models and tests of interaction effects will be performed when relevant. In the case of interaction effects, stratified results will be presented. All tests will be two-sided and $p<0.05$ will be considered statistically significant. All statistical analyses will be performed using Stata.

\section{Analysis plan}

We plan to conduct the following analyses to test our hypotheses:

- Hypothesis 1.1: A prospective cohort analysis of prediagnostic BMI and other anthropometric measures in relation to $\mathrm{CM}$ risk, Breslow thickness and mortality using the complete Janus Cohort $(\mathrm{n}=292851)$.

- Hypothesis 1.2: A prospective analysis of survival after a CM diagnosis, according to prediagnostic BMI $(\mathrm{n} \approx$ $3000)$.

- Hypothesis 1.3: A prospective cohort analysis of prediagnostic BMI and the risk of second cancer after a CM diagnosis using the complete Janus Cohort $(\mathrm{n}=292851)$.

- Hypothesis 1.4: A prospective cohort analysis of prediagnostic BMI and the risk of second cancer among CM survivors $(n \approx 3000)$.

- Hypothesis 2.1: A nested case-control analysis of CM risk and Breslow thickness according to prediagnostic serum levels of $25(\mathrm{OH}) \mathrm{D}$ and leptin in 700 pairs.

- Hypothesis 2.2: A prospective analysis of survival after a CM diagnosis $(n=700)$ according to prediagnostic serum levels of $25(\mathrm{OH}) \mathrm{D}$ and leptin.

- Hypothesis 2.3: A nested case-control analysis of risk of second cancer after a CM diagnosis according to prediagnostic serum levels of $25(\mathrm{OH}) \mathrm{D}$ and leptin. Using 345 pairs of cases with $\mathrm{CM}+$ a second cancer and controls without a cancer history.

- Hypothesis 2.4: A nested case-control analysis of risk of second cancer among CM survivors according to prediagnostic serum levels of $25(\mathrm{OH}) \mathrm{D}$ and leptin. Using 345 pairs of cases with $\mathrm{CM}+$ a second cancer and controls with a $\mathrm{CM}$ diagnosis.

- Hypothesis 2.5: A nested case-control analysis investigating risk of lymphoma after CM or vice versa according to prediagnostic serum levels of $25(\mathrm{OH}) \mathrm{D}$ ( $\mathrm{n}=60$ cases) compared with controls without a cancer history.

\section{Project strengths and limitations}

A major strength of the project is the linkage of multiple data sources by use of the PIN, thereby establishing a comprehensive research file with independently and prospectively collected data, and a complete control of loss to follow-up. An important strength is also the use of high-quality cancer data with over $3000 \mathrm{CM}$ cases from a population-based registry relying on compulsory reporting of incident cancers. Further, the prediagnostic serum samples assure a clear prospective temporal relationship between exposure and cancer, which limits the possibility of reverse causality, that is, that the cancer or its precursor affects the $25(\mathrm{OH}) \mathrm{D}$ or leptin serum levels.

An important limitation of the project is that we will only be able to obtain group-level data on UVR exposure (ambient UVA, UVB and ERY; sunburns, sunbathing vacations and solarium use), but our data will capture variation in these variables by age, time period and between counties. However, the long and complete time series, covering the whole observation period and early childhood for many of the participants, enables analysis with time-varying UVR exposure. Another limitation is the lack of data on pigmentary characteristics and number of naevi. Also, differences in skin colour between cases and controls could potentially bias our estimates. However, the average fraction of non-whites during 1970-1991 (when 97\% of the Janus Cohort was established) was less than $1 \%$ of the total Norwegian population, ${ }^{68}$ and hence we consider the risk of introducing bias by not taking individual information on skin colour into account as negligible.

\section{ETHICS AND DISSEIMINATION}

The project has a running approval from the Regional Committee for Medical and Health Research Ethics to link the different population-based registries to establish a deidentified research file. In addition, each registry and data source has approved that its data will be linked and used in a deidentified research file. A linkage key consisting of the 11-digit PIN and a project-specific ID number will be stored and governed by a third party unavailable to the research team. Moreover, participation in each of the health surveys constituting the Janus Cohort was voluntary and based on informed consent.

All results will be published in relevant peer-reviewed international scientific journals and presented at conferences, nationally and internationally. Results will also be directly communicated to user groups such as the Norwegian Cancer Society, The Norwegian Melanoma Association, and to health authorities and clinicians. Both the annual Norwegian conferences ('Oncologic Forum', the Norwegian Melanoma Group Meeting) and international conferences will serve as platforms for knowledge distribution to clinicians and researchers. Important results will also be disseminated through press releases. Further, lectures, the CRN website, social media and other potential channels will also be used to reach patient organisations, patients and the general public. 
Correction notice This paper has been amended since it was published Online First. Owing to a scripting error, some of the publisher names in the references were replaced with 'BMJ Publishing Group'. This only affected the full text version, not the PDF. We have since corrected theseerrors and the correct publishers have been inserted into the references.

Acknowledgements The authors thank Hilde Langseth, Marianne Lauritzen, Tove Slyngstad, Kirsti Vik Hjerkind, Jan Ivar Martinsen and Elina Vinberg at the Janus Serum Bank/Cancer Registry of Norway and Sven Ove Samuelsen at the Department of Mathematics, University of Oslo, for valuable assistance in planning this project. Further, we also thank Lill Tove Nilsen and Bjørn Johnsen at the Norwegian Radiation Protection Authority and Reza Ghiasvand at the Department of Biostatistics, University of Oslo, for the development of the UVR exposure data.

Contributors TER conceived the study. JSS, TKG, JRR, LV, RB, MBV and TER contributed to the project design. TER and JSS are responsible for data acquisition. JSS and TER drafted the manuscript, and MBV, TKG, JRR, LV and RB reviewed and revised it critically for important intellectual content and approved the final version for submission. JSS and TER are the guarantors.

Funding The research project has been reviewed and granted funding by the Norwegian Cancer Society (no 5829980-2014) and the Cancer Registry of Norway Research Fund.

\section{Competing interests None declared.}

Ethics approval This project has approval from the Regional Committee for Medical and Health Research Ethics (no 2014/185).

Provenance and peer review Not commissioned; externally peer reviewed.

Data sharing statement Requests for data sharing/case pooling may be directed to the corresponding author. This project uses third-party data derived from State government registries, which are ultimately governed by their ethics committees and data custodians. Thus, any requests to share these data will be subject to formal approval from each data source used in this project.

Open Access This is an Open Access article distributed in accordance with the Creative Commons Attribution Non Commercial (CC BY-NC 4.0) license, which permits others to distribute, remix, adapt, build upon this work non-commercially, and license their derivative works on different terms, provided the original work is properly cited and the use is non-commercial. See: http://creativecommons.org/ licenses/by-nc/4.0/

(c) Article author(s) (or their employer(s) unless otherwise stated in the text of the article) 2017. All rights reserved. No commercial use is permitted unless otherwise expressly granted.

\section{REFERENCES}

1. IARC. Solar and ultraviolet radiation. Monographs on the evaluation of carcinogenic risks to humans. Lyon: IARC, 1992.

2. IARCA review of human carcinogens: radiation. Monographs on the evaluation of carcinogenic risks to humans.Lyon: IARC 2012:35-101.

3. Gandini S, Sera F, Cattaruzza MS, et al. Meta-analysis of risk factors for cutaneous melanoma: II. Sun exposure. Eur J Cancer 2005;41:45-60.

4. Siskind V, Whiteman DC, Aitken JF, et al. An analysis of risk factors for cutaneous melanoma by anatomical site (Australia). Cancer Causes Control 2005;16:193-9.

5. Bataille V, de Vries E. Melanoma-Part 1: epidemiology, risk factors, and prevention. BMJ 2008;337:a2249.

6. Veierod MB, Adami HO, Lund E, et al. Sun and solarium exposure and melanoma risk: effects of age, pigmentary characteristics, and nevi. Cancer epidemiology, biomarkers \& prevention: a publication of the American Association for Cancer Research, cosponsored by the American Society of Preventive Oncology. 2010;19:111-20.

7. Gruber S, Armstrong B. Cutaneous and ocular melanoma. In: Schottenfeld D, Fraumeni JF, eds. Cancer epidemiology and prevention. New York: Oxford University Press, 2006:1196-229.

8. Ferlay J, Steliarova-Foucher E, Lortet-Tieulent J, et al. Cancer incidence and mortality patterns in Europe: estimates for 40 countries in 2012. Eur J Cancer 2013;49:1374-403.

9. Whiteman DC, Green AC, Olsen CM. The growing burden of invasive melanoma: projections of incidence rates and numbers of new cases in six susceptible populations through 2031. J Invest Dermatol 2016;136:1161-71.
10. Robsahm TE, Bergva G, Hestvik UE, et al. Sex differences in rising trends of cutaneous malignant melanoma in Norway, 1954-2008. Melanoma Res 2013;23:70-8.

11. Sergentanis TN, Antoniadis AG, Gogas HJ, et al. Obesity and risk of malignant melanoma: a meta-analysis of cohort and case-control studies. Eur J Cancer 2013;49:642-57.

12. Caini S, Boniol M, Tosti G, et al. Vitamin D and melanoma and nonmelanoma skin cancer risk and prognosis: a comprehensive review and meta-analysis. Eur J Cancer 2014;50:2649-58.

13. Bikle D. Nonclassic actions of vitamin D. J Clin Endocrinol Metab 2009;94:26-34.

14. Tang JY, Fu T, Lau C, et al. Vitamin D in cutaneous carcinogenesis: part I. J Am Acad Dermatol 2012;67:803 e1-12.

15. Krishnan AV, Feldman D. Mechanisms of the anti-cancer and antiinflammatory actions of vitamin D. Annu Rev Pharmacol Toxicol 2011;51:311-36.

16. Townsend K, Evans KN, Campbell MJ, et al. Biological actions of extra-renal 25-hydroxyvitamin D-1alpha-hydroxylase and implications for chemoprevention and treatment. J Steroid Biochem Mol Biol 2005;97:103-9.

17. Tuohimaa P, Lou YR. Optimal serum calcidiol concentration for cancer prevention. Anticancer Res 2012;32:373-81.

18. Afzal S, Nordestgaard BG, Bojesen SE. Plasma 25-hydroxyvitamin D and risk of non-melanoma and melanoma skin cancer: a prospective cohort study. J Invest Dermato/ 2013;133:629-36.

19. Major JM, Kiruthu C, Weinstein SJ, et al. Pre-diagnostic circulating vitamin D and risk of melanoma in men. PLoS One 2012;7:e35112.

20. Randerson-Moor JA, Taylor JC, Elliott F, et al. Vitamin D receptor gene polymorphisms, serum 25-hydroxyvitamin D levels, and melanoma: UK case-control comparisons and a meta-analysis of published VDR data. Eur J Cancer 2009;45:3271-81.

21. van der Pols JC, Russell A, Bauer U, et al. Vitamin D status and skin cancer risk independent of time outdoors: 11-year prospective study in an Australian community. J Invest Dermatol 2013;133:637-41.

22. Fang $S$, Sui $D$, Wang $Y$, et al. Association of vitamin $D$ levels with outcome in patients with melanoma after adjustment for C-reactive protein. J Clin Oncol 2016;34:1741-7.

23. Gambichler T, Bindsteiner M, Höxtermann S, et al. Serum 25-hydroxyvitamin D serum levels in a large German cohort of patients with melanoma. Br J Dermatol 2013;168:625-8.

24. Newton-Bishop JA, Beswick S, Randerson-Moor J, et al. Serum 25-hydroxyvitamin D3 levels are associated with breslow thickness at presentation and survival from melanoma. $J$ Clin Oncol 2009;27:5439-44.

25. Wyatt C, Lucas RM, Hurst C, et al. Vitamin D deficiency at melanoma diagnosis is associated with higher Breslow thickness. PLoS One 2015;10:e0126394.

26. Berwick M, Erdei EO. Vitamin D and melanoma incidence and mortality. Pigment Cell Melanoma Res 2013;26:9-15.

27. Robsahm TE, Schwartz GG, Tretli S. The inverse relationship between 25-hydroxyvitamin D and cancer survival: discussion of causation. Cancers 2013;5:1439-55.

28. Saiag P, Aegerter P, Vitoux D, et al. Prognostic value of 25-hydroxyvitamin D3 levels at diagnosis and during follow-up in melanoma patients. J Natl Cancer Inst 2015;107:djv264.

29. Mai XM, Chen Y, Camargo CA, et al. Cross-sectional and prospective cohort study of serum 25-hydroxyvitamin D level and obesity in adults: the HUNT study. Am J Epidemiol 2012;175:1029-36.

30. Foss YJ. Vitamin D deficiency is the cause of common obesity. Med Hypotheses 2009;72:314-21.

31. Holick MF. Vitamin D deficiency. N Engl J Med 2007;357:266-81.

32. Pereira-Santos M, Costa PR, Assis AM, et al. Obesity and vitamin $D$ deficiency: a systematic review and meta-analysis. Obes Rev 2015;16:341-9.

33. Vanlint S. Vitamin D and obesity. Nutrients 2013;5:949-56

34. Pandey V, Vijayakumar MV, Ajay AK, et al. Diet-induced obesity increases melanoma progression: involvement of Cav-1 and FASN. Int J Cancer 2012;130:497-508.

35. Stattin P, Björ O, Ferrari P, et al. Prospective study of hyperglycemia and cancer risk. Diabetes Care 2007:30:561-7.

36. Cao Y. Angiogenesis modulates adipogenesis and obesity. J Clin Invest 2007;117:2362-8.

37. Klok MD, Jakobsdottir S, Drent ML. The role of leptin and ghrelin in the regulation of food intake and body weight in humans: a review. Obes Rev 2007;8:21-34

38. Calle EE, Kaaks R, Overweight KR. Overweight, obesity and cancer: epidemiological evidence and proposed mechanisms. Nat Rev Cancer 2004;4:579-91.

39. Gogas H, Trakatelli M, Dessypris N, et al. Melanoma risk in association with serum leptin levels and lifestyle parameters: a casecontrol study. Ann Oncol 2008;19:384-9. 
40. Morpurgo G, Fioretti B, Catacuzzeno L. The increased incidence of malignant melanoma in obese individuals is due to impaired melanogenesis and melanocyte DNA repair. Med Hypotheses 2012;78:533-5.

41. Brandon EL, Gu JW, Cantwell L, et al. Obesity promotes melanoma tumor growth: role of leptin. Cancer Biol Ther 2009;8:1871-9.

42. Ellerhorst JA, Diwan AH, Dang SM, et al. Promotion of melanoma growth by the metabolic hormone leptin. Oncol Rep 2010;23:901-7.

43. Leptin M. Obesity and cutaneous melanoma. Br J Dermatol 2012;166:1358-9.

44. Oba J, Wei W, Gershenwald JE, et al. Elevated serum leptin levels are associated with an increased risk of sentinel lymph node metastasis in cutaneous melanoma. Medicine 2016;95:e3073.

45. Robsahm TE, Karagas MR, Rees JR, et al. New malignancies after squamous cell carcinoma and melanomas: a population-based study from Norway. BMC Cancer 2014;14:210.

46. Curtis RE, Freedmanm DM, Ron E, eds. New malignancies among cancer survivors: SEER cancer registries, 1973-2000. Bethesda, MD: National Cancer Institute, NIH, 2006.

47. Morton LM, Curtis RE, Linet MS, et al. Second malignancy risks after non-Hodgkin's lymphoma and chronic lymphocytic leukemia: differences by lymphoma subtype. J Clin Oncol 2010;28:4935-44.

48. Lam CJ, Curtis RE, Dores GM, et al. Risk factors for melanoma among survivors of non-Hodgkin lymphoma. J Clin Oncol 2015;33:3096-104.

49. Aref S, Ibrahim L, Azmy E. Prognostic impact of serum 25-hydroxyvitamin D [25(OH)D] concentrations in patients with lymphoid malignancies. Hematology 2013;18:20-5.

50. Drake MT, Maurer MJ, Link BK, et al. Vitamin D insufficiency and prognosis in non-Hodgkin's lymphoma. J Clin Oncol 2010;28:4191-8.

51. Langseth H, Gislefoss RE, Martinsen Jl, et al. Cohort profile: the Janus Serum Bank Cohort in Norway. Int J Epidemiol 2016:dyw027.

52. Agborsangaya C, Toriola AT, Grankvist K, et al. The effects of storage time and sampling season on the stability of serum 25-hydroxy vitamin D and androstenedione. Nutr Cancer 2010;62:51-7.

53. Flower L, Ahuja RH, Humphries SE, et al. Effects of sample handling on the stability of interleukin 6 , tumour necrosis factor-alpha and leptin. Cytokine 2000;12:1712-6.
54. Meyer HE, Robsahm TE, Bjørge T, et al. Vitamin D, season, and risk of prostate Cancer: a nested case-control study within Norwegian health studies. Am J Clin Nutr 2013;97:147-54.

55. Tretli S, Hernes E, Berg JP, et al. Association between serum $25(\mathrm{OH})$ $\mathrm{D}$ and death from prostate cancer. Br J Cancer 2009;100:450-4.

56. Stattin P, Lukanova A, Biessy C, et al. Obesity and colon cancer: does leptin provide a link? Int J Cancer 2004;109:149-52.

57. Stattin P, Palmqvist R, Söderberg S, et al. Plasma leptin and colorectal cancer risk: a prospective study in Northern Sweden. Oncol Rep 2003;10:2015-21.

58. Hjerkind KV, Gislefoss RE, Tretli S, Nystad S.;, et al. Cohort profile update: the Janus Serum Bank Cohort in Norway. Int J Epidemiol. In Press. 2017;2016.

59. Nürnberg B, Gräber S, Gärtner B, et al. Reduced serum 25-hydroxyvitamin D levels in stage IV melanoma patients. Anticancer Res 2009;29:3669-74.

60. Medhaug I, Olseth JA, Reuder J. UV radiation and skin cancer in Norway. J Photochem Photobiol B Biol 2009;96:232-41.

61. Lund E, Dumeaux V, Braaten T, et al. Cohort profile: the Norwegian Women and Cancer Study-NOWAC-Kvinner og kreft. Int $J$ Epidemiol 2008;37:36-41.

62. Ghiasvand R, Lund E, Edvardsen K, et al. Prevalence and trends of sunscreen use and sunburn among Norwegian women. $\mathrm{Br} J$ Dermatol 2015;172:475-83.

63. Norwegian Cancer Society. Solvaner i den norske befolkningen (Sunhabits in the Norwegian population). Report in Norwegian 2012.

64. Cancer Registry of Norway. Cancer in Norway 2015. 2016 https:// www.kreftregisteret.no/globalassets/cancer-in-norway/2015/cin 2015.pdf.

65. Pearce N. What does the odds ratio estimate in a case-control study? Int J Epidemiol 1993;22:1189-92.

66. Frigstad SO, Hoivik M, Jahnsen J, et al. Vitamin D deficiency in inflammatory bowel disease: prevalence and predictors in a Norwegian outpatient population. Scand J Gastroenterol 2016:1-7.

67. Lee $\mathrm{KH}$, Bartsch $\mathrm{H}$, Nair J, et al. Effect of short-term fasting on urinary excretion of primary lipid peroxidation products and on markers of oxidative DNA damage in healthy women. Carcinogenesis 2006;27:1398-403.

68. Statistics-Norway. Immigrants and Norwegian-born to immigrant parents. 2017: Statistics Norway. https://www.ssb.no/en/befolkning/ statistikker/innvbef. (accessed 20 Mar 2017). 